\title{
Effect of Structural Rearrangements on Chiasma Frequency in Mouse Oocytes
}

\author{
Georgiana M. Jagiello, Jye-Siung Fang and Mercedes B. Ducayen \\ Departments of Obstetrics and Gynecology, Genetics and Development, and Center for \\ Reproductive Sciences of the International Institute for the Study of Human \\ Reproduction, College of Physicians and Surgeons of Columbia \\ University, 630 West 168th Street, New York, N. Y. 10032
}

Accepted August 24, 1990

Interchromosomal effects of structural or numerical alterations on crossing over have been demonstrated for several species. Among these were examinations in the affected chromosomes of Drosophila with para-or pericentric inversions (Barbanova et al. 1985, Lucchesi and Suzuki 1968, Schultz and Redfield 1951, White and Morley 1955), centric fission and interchanges in Hypochoeris radicata (Parker et al. 1982), autosomal-autosomal translocations in Drosophila (Hinton 1965) and translocations in Caenorhabditis elegans (McKim et al. 1988). Effects on the total genome have varies with species, some showing increases in total chiasma frequency (Hewitt 1987), some showing no significant change (Sybenga 1967). It was the purpose of the present work to examine the possibility of such effects on recombination as measured by total chiasma complements during mouse oogenesis, since no data on this provocative question have been published in female mammals.

\section{Materials and Methods}

60-90 day old female mice bearing Robertsonian translocations, paracentric inversions, balanced Cattanach's and Searle's translocation and XO genotypes were donors. The homozygous Robertsonian mice were mated with CBA/J or C57BL/6J. The Cattanach, Searle and XO mice were mated with CBA/J. The homozygous paracentric inversion bearing mice were mated with DBA/2J males. Day of vaginal plug was designated as Day 0 of gestation. Chiasma frequencies were scored in early diplotene oocytes derived from fetal ovaries of heterozygous offspring on gestational day 18 (Fig. 1).

The four Robertsonian translocations selected for study were Rb (11.13) 4Bnr, Rb (1.3) 1Bnr, Rb (4.15) 4Rma, and Rb (5.15) 15Rma. The oocytes from heterozygous Rb1Bnr, Rb4Rma and Rb15Rma feti were compared with control CBA/J oocytes (Table 1). Balanced Cattanach's translocation [Is (In 7; X) 1Ct] fetal oocytes, balanced Searle's translocation $[\mathrm{T}(\mathrm{X} ; 16) 16 \mathrm{H}]$ oocytes and the oocytes of XX offspring from XO mothers were also compared to control CBA/J oocytes. The chiasma frequencies of oocytes from Rb (11.13) $4 \mathrm{Bnr}$ were compared to control $\mathrm{C} 57 \mathrm{BL} / 6 \mathrm{~J}$ since the homozygote $\mathrm{Rb}$ (11.13) 4Bnr females were crossed with $\mathrm{C} 57 \mathrm{BL} / 6 \mathrm{~J}$ males. Diplotene oocytes from three paracentric inversions, In (1) $1 \mathrm{Rk}$, In (5) $2 \mathrm{Rk}$ and In $(\mathrm{X}) 1 \mathrm{H}$ were compared with $\mathrm{DBA} / 2 \mathrm{~J}$ fetal oocytes. Parental chromosome complement was ascertained by examination of $\mathrm{G}$ banded mitotic metaphase cells from bone marrow prepared by a modification of the method of Tjio and Whang (1962). Fetal chromosomal complement was determined from oogonial metaphase cells found among the meiotic cells prepared as described below.

Cytologic preparations of diplotene oocytes were made by the method of Jagiello and Fang (1987). Briefly, day 18 fetal ovaries were dissected, cleaned, placed in $0.05 \mathrm{M} \mathrm{KCl}$ at 
$38^{\circ} \mathrm{C}$ for 1 hour, fixed with 3: 1 absolute ethanol: glacial acetic acid and squashed/smeared in a drop of fixative on clean, wet slides. Preparations were stained with $2 \%$ Giemsa in water (Fisher 50-G-28) for 5-10 minutes and air-dried. Intact, well-spread early diplotene oocytes were scored for chiasma number by three independent observers using a Planapo 100X objective of a Zeiss Photomicroscope II. Chiasma scores for each genotype were found to be consonant among the observers. The chiasma counts were compared with appropriate controls using the t-test (Snedecor 1956).
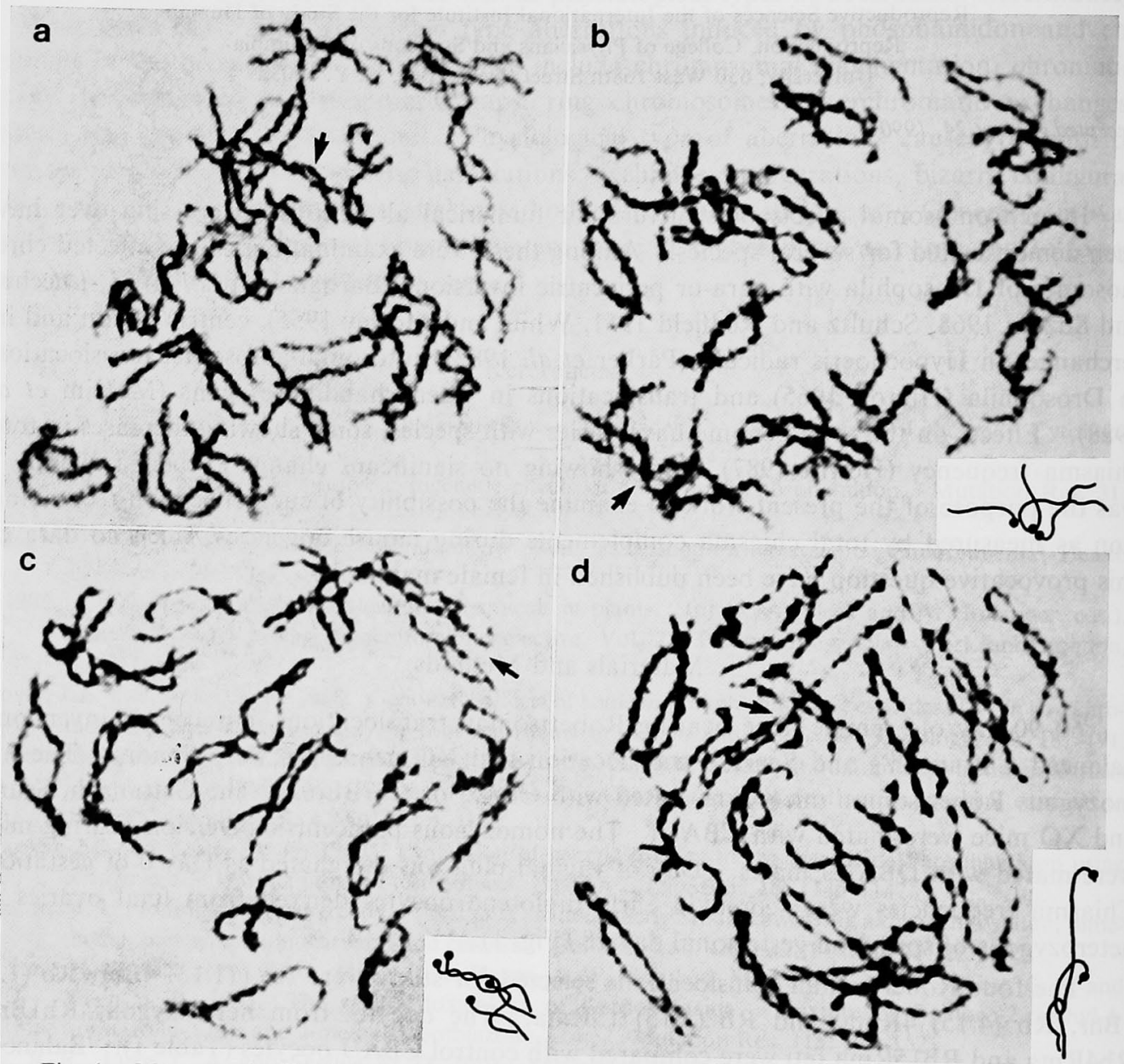

Fig. 1. Mouse early diplotene oocytes. a, control DBA/2J. X-bivalent identified by size and chromomere pattern (arrow) $1290 \times$. Total chiasmata $=27$. b, Robertsonian translocation, $R b$ (5.15) 15Rma, trivalent (5.15) (arrow) $1290 \times$. Insert, line drawing. Total chiasmata $=25$. c, Searle's translocation, T $(X ; 16) 16 \mathrm{H}$, quadrivalent $(X ; 16)$ (arrow) $1390 \times$. Insert, line drawing. Total chiasmata $=27$. d, inversion, In (1) $1 \mathrm{Rk}$, bivalent 1 (arrow) $1580 \times$. Insert, line drawing.

Total chiasmata $=27$.

\section{Results and discussion}

The chiasma data for all genotypes studied are summarized in Table 1. It can be seen that a significant decrease occurred in total chiasma per oocyte or per bivalent in all Robertsonian translocations (except for the Rb (1.3) 1Bnr), Cattanach's and Searle's rearrangements, $\mathrm{XX}$ progeny of $\mathrm{XO}$ mothers and the three paracentric inversions. These data support 
the concept (Schultz and Redfield 1951) that structural or numerical alterations in a genome may have intra-and interchromosomal effects on crossing over. The data also support the concept that reduced crossing over in a genome correlates with increased non-disjunction (Mather 1938), a common finding reported for the structural rearrangements studied (Green 1981). Reports in any species, particularly mammalian, of a decrease in total crossing over in germ cells of heterozygotes with various structural alterations have not been published, yet the mouse genotypes studied here represent a variety of chromosome breakpoints and movements of eu-and heterochromatin in the female mouse oocyte complement. In addition, an effect of the aneuploidy of the XO mother leading to a surprising reduction of the total chiasma frequency in $X X$ offspring suggests perturbation of recombination phenomena. Proposed hypotheses of interchromosomal effects such as position effects, nonhomologous associations, disruption of "factors" required for crossing over or inhibition of heterochromatin function (Lucchesi and Suzuki 1968, Lucchesi 1976) may explain these data, but it must be

Table 1. Chiasma Frequencies of Mouse Early Diplotene Oocytes

\begin{tabular}{lccccc}
\hline \multicolumn{1}{c}{ Genotype } & $\begin{array}{c}\text { Total } \\
\text { Chiasmata }\end{array}$ & $\begin{array}{c}\text { Total } \\
\text { Oocytes }\end{array}$ & $\begin{array}{c}\text { Chiasmata } \\
\text { per } \\
\text { Oocytes }\end{array}$ & $\begin{array}{c}\text { Chiasmata } \\
\text { per } \\
\text { Bivalent** }\end{array}$ & P value \\
\hline CBA/J*** & 3020 & 112 & 26.97 & 1.35 & -317 \\
Rb (1.3) 1Bnr & 2610 & 100 & 26.10 & 1.31 & $<0.17$ \\
Rb (4.15) 4Rma & 4707 & 184 & 25.59 & 1.28 & $<0.01^{*}$ \\
Rb (5.15) 15Rma & 2378 & 95 & 25.04 & 1.26 & $<0.001^{*}$ \\
Is (In 7; X) 1Ct & 2315 & 95 & 24.75 & 1.22 & $<0.001^{*}$ \\
T (X; 16) 16H & 1211 & 51 & 23.75 & 1.19 & $<0.001^{*}$ \\
XX (XO) & 1806 & 76 & 23.77 & 1.19 & $<0.001^{*}$ \\
\hline C57BL/6J*** & 2784 & 89 & 31.28 & 1.57 & - \\
Rb (11.13) 4Bnr & 6610 & 228 & 29.00 & 1.45 & $<0.001^{*}$ \\
\hline DBA/2J*** & 1487 & 50 & 29.74 & 1.49 & - \\
In (1) 1Rk & 1843 & 72 & 25.60 & 1.28 & $<0.001^{*}$ \\
In (5) 2Rk & 2344 & 91 & 25.76 & 1.29 & $<0.001^{*}$ \\
In (X) 1H & 1445 & 57 & 25.35 & 1.27 & $<0.001^{*}$ \\
\hline
\end{tabular}

* = Statistically significant.

**=Including trivalents of Robertsonian translocations (total chiasmata divided by 20).

$* * *=$ Controls.

considered that altering the architecture of the female mouse genome by translocations, inversions, or aneuploidy affects the control of crossing over by mechanisms yet to be discovered.

\section{Abstract}

A study of total chiasma frequencies in the diplotene oocytes of mice heterozygous for Robertsonian translocations, $\mathrm{X}$-autosomal translocations, paracentric inversions as well as the XX progeny of XO mothers revealed a decrease in all but one genotype. These data present the first analysis of potential interchromosomal effects on crossing over in mouse oogenesis.

\section{Acknowledgment}

The authors are very grateful to Dr. T. A. Roderick for making the inversion mice available and to Dr. Felix de La Cruz of NICHD for making other strains available through the Mouse Model Program. This work was supported by NICHD. 


\section{Literature cited}

Barbanova, L. V., Mamon, L. A. and Vatti, K. V. 1985. Crossing over in the translocation heterozygotes with break point mapping outside the pericentric region of chromosomes 2 and 3 of Drosophila melanogaster. Sov. Genet. 21 : 1560.

Green, M. C. In: Genetic Variants and Strains of the Laboratory Mouse. Verlag; New York 1981. Chapter 7, pp. 324-359.

Hewitt, G. M. 1987. An interchange which raises chiasma frequency. Chromosoma (Berl.) 21: 285.

Hinton, C. W. 1965. The effects of heterozygous autosomal translocations on recombination in the X chromosome of Drosophila melanogaster. Genetics 51: 971.

Jagiello, G. and Fang, J. S. 1987. Observations on chiasmata in mouse diplotene oocytes and spermatocytes. Cytologia 52: 283.

Lucchesi, J. C. and Suzuki, D. T. 1968. The interchromosomal control of recombination. Ann. Rev. Genet. 2: 53 .

- 1976. Interchromosomal effects. The Genetics and Biology of Drosophila (Ashsburner M. and Novitski, E. eds). New York: Academic Press. pp. 315.

Mather, K. 1938. Crossing-over. Biol. Rev. 13: 252.

McKim, K. S., Howell, A. M. and Rose, A. M. 1988. The effects of translocations on recombination frequency in Caenorhabditis elegans. Genetics 120: 987.

Parker, J. S., Palmer, R. W., Whitehorn, M. A. F. and Edgar, L. A. 1982. Chiasma frequency effects of structural chromosome change. Chromosoma (Berl.) 85: 673.

Schultz, J. and Redfield, H. 1951. Interchromosomal effects on crossing over in Drosophila. Cold Spring Harbor Symp. Quant. Biol. 16: 175.

Snedecor, G. W. 1956. Statistical Methods. Iowa State University Press, Ames, Iowa.

Sybenga, J. 1967. Interchromosome effects on chiasma frequencies in rye. Genetica 38: 171.

Tjio, J. H. and Whang J. 1962. Chromosome preparations of bone marrow cells without prior in vitro culture or in vivo colchicine administration. Stain Technol. 37: 17.

White, M. J. D., Morley, F. H. W. 1955. Effects of pericentric rearrangements on recombination in grasshopper chromosome. Genetics 40: 604 . 